\title{
Perancangan Furniture Multifungsi Kamar Kos Mahasiswa di Surabaya Dengan Pendekatan Ergonomi
}

\author{
Joel Heryanto $^{1 *}$, Markus Hartono ${ }^{1}$, I Made Ronyastra ${ }^{1}$ \\ ${ }^{1}$ Jurusan Teknik Industri, Fakultas Teknik, Universitas Surabaya, Raya Kalirungkut Surabaya-Indonesia \\ 60293 \\ *corresponding author: heryantojoel@gmail.com
}

\begin{abstract}
Boarding house is one of the vertical dwellings with certain tariffs which are useful as temporary residences, both those who study far from their homes or work in uncertain locations. With ongoing price inflation, the boarding house entrepreneurs will optimize development for their business, one of which will affect the size of the boarding room. Retrieval of data using interview techniques with a sample system. Interviews were conducted so that this study uses an ergonomics approach and product design, so that the products created are suitable and comfortable when used. Ergonomics will be combined with anthropometry, with the aim that the product is created with a very comfortable size and product design is used to help arrange and sort the best product design. The results of data processing get a multifunctional room furniture concept that uses a modern design with a size of $2.2 \mathrm{~m} x$ $2 m \times 2 m$, using full wood raw material and has a bed and folding table, has a drawer and cupboard. This concept will be shown to boarders and boarding entrepreneurs, $90 \%$ of 20 resource persons expressed interest in this concept. After calculating the selling price, this product is valued at $R p .3,050,000$. After conducting market testing, no one is interested in buying this product.
\end{abstract}

Keywords: boarding house, design, price

\begin{abstract}
Abstrak-Kos merupakan salah satu hunian vertikal dengan tarif tertentu yang berguna sebagai tempat tinggal sementara, baik itu yang menempuh pendidikan di luar tempat tinggal atau bekerja pada lokasi yang tidak menentu. Dengan inflasi harga berkelanjutan membuat parar pengusaha kos akan mengoptimalkan pembangunan untuk bisnis mereka, salah satunya akan berdampak pada ukuran kamar kos. Pengambilan data menggunakan teknik interview dengan sistem sampel. Interview dilakukan agar Penelitian ini menggunakan pendekatan ergonomi dan perancangan produk, agar produk yang diciptakan sesuai dan nyaman saat digunakan. Ergonomi akan dipadukan dengan antropometri yang bertujuan produk diciptakan dengan ukuran yang sangat nyaman dan perancangan produk digunakan untuk membantu dalam merangkai dan memilah rancangan produk yang paling baik. Hasil dari pengolahan data mendapatkan konsep Furniture kamar multifungsi yang menggunakan desain modern dengan ukuran $2.2 \mathrm{~m} \times 2 \mathrm{~m} \times 2 \mathrm{~m}$, menggunakan bahan baku full kayu serta memiliki ranjang dan meja lipat, memiliki laci dan lemari. Konsep ini akan ditunjukan terhadap penghuni kos dan pengusaha kos, 90\% dari 20 narasumber menyatakan berminat terhadap konsep ini. Setelah dilakukan perhitungan untuk harga jual, produk ini dihargai sebesar Rp. 3.050.000. Setelah dilakukan market testing, produk belum ada yang berminat untuk membelinya.
\end{abstract}

Kata kunci: kos, desain, harga

\section{PENDAHULUAN}

Seiring berjalannya waktu, populasi manusia terus meningkat dengan pesat. Tercatat pada tahun 2018, Indonesia mempunyai jumlah penduduk 266,79 juta jiwa mengacu pada data Perserikatan Bangsa Bangsa (PBB). Diperkirakan pada tahun 2020 mencapai 271 juta jiwa. Hal tersebut dipicu bukan dikarenakan angka kelahiran yang meningkat melainkan proses urbanisasi yang dilakukan oleh sebagian orang. Penambahan jumlah penduduk secara signifikan tanpa diikuti tempat tinggal yang memadai memerlukan penanganan secara khusus. Banyak yang beralih dari hunian horizontal ke vertikal sebab harga yang terus merangkak naik.

Hunian vertikal merupakan tempat tinggal tersusun bertingkat yang dipakai oleh banyak orang. Banyak kota padat yang mulai menerapkan cara ini untuk mengatasi minimalnya lahan yang dapat diubah menjadi tempat huni. Beberapa contoh hunian vertikal ialah apartemen, indekos, dan rumah susun. Saat ini lagi maraknya pembukaan lahan untuk membangun indekos atau kos. Kita dapat menjumpai indekos atau kos pada sejumlah titik yang ramai terutama universitas atau kampus. Kos merupakan salah satu pilihan bagi para mahasiswa yang sedang menimba ilmu jauh dari tempat tinggalnya. Seiring terjadinya inflasi harga tiap tahunnya, akan membuat para pelaku usaha kos berpikir dua kali dalam 
mengeksekusi rencananya. Salah satu cara agar BEP dengan cepat adalah menambah jumlah kamar kos yang berimbas dengan pengurangan luas ruang agar bangunan lebih optimal. Dampak yang akan terjadi adalah kenyamanan penghuni kos akan berkurang, kondisi kamar yang semakin sesak, bahkan kesehatan dari penghuni dapat terganggu. Setelah melakukan observasi secara langsung, tidak sedikit kamar kos yang dibanderol harga sewa Rp. 1.500 .000 sampai Rp. 2.000.000 kurang dari kata nyaman. Penyebabnya banyak barang penghuni yang berantakan tidak tersimpan dengan rapi dan perabot yang menyita ruang kamar cukup banyak. Akibatnya beberapa aktivitas penghuni tidak dapat dilakukan dengan baik bahkan kegiatan aktivitas sering dilakukan tidak pada tempatnya, seperti saat makan tidak bisa di meja karena penuh dengan barang pribadi, tugas, dan ATK.

Dengan demikian, dirasakan perlu adanya suatu dobrakan inovasi produk perabot yang dapat menjawab kebutuhan dari penghuni kos. Produk ini dapat menjadi solusi bagi kos yang berukuran $3 \mathrm{~m} \times 3.5 \mathrm{~m}$ sesuai dengan acuan penelitian ini. Karena aktivitas dapat dilakukan tanpa hambatan ruang gerak yang terbatas, selain itu mempunyai tempat penyimpanan yang cukup sehingga ruangan menjadi ringkas dan rapi. Penelitian ini menggunakan data yang didapat dari interview kepada para penghuni kos. Terdapat batasan pada pengumpulan data karena kondisi kos disesuaikan hanya pada area Surabaya.

Pada penelitian terdahulu yang terkait dengan penelitian ini antara lain membuat rancangan furniture tempat tidur pada rusun, kemudian perancangan sistem furniture perpustakaan multifungsi untuk balita di dalam rumah dengan pendekatan ergonomi. Penelitian Tugas Akhir ini membuat rancangan furniture multifungsi kamar kos yang mengandung prinsip ergonomi guna menyelerasikan atau menyeimbangkan antara segala fasilitas yang digunakan baik dalam beraktivitas maupun istirahat dengan kemampuan dan keterbatasan manusia baik fisik maupun mental sehingga kualitas hidup secara keseluruhan menjadi lebih baik (Tarwaka, 2004), dengan acuan ukuran disesuaikan dengan data antropometri laki-laki dan perempuan berusia 16- 30 tahun.

\section{METODE}

Pengamatan awal dilakukan dengan melakukan survei secara langsung pada kamar kos, terutama di sekitar universitas. Penghuni kos disekitar universitas tidak hanya dihuni oleh mahasiswa namun terdapat orang yang sudah bekerja bahkan sampai anak yang masih SMA dan SMP. Setiap unit kamar kos terdiiri dari 3 komponen utama perabot, yaitu ranjang, meja belajar, dan lemari. Pada umumnya ketika saat baru menggunakan kamar tersebut masih biasa saja, kondisi ruangan tertata rapi dan tidak banyak barang. Ketika sudah beberapa waktu banyak ditemukan kamar kos yang berantakan dan penuh sesak dengan barang. Kebanyakan barang pribadi yang tidak dapat ditata dengan rapi menjadi penyebabnya karena ketersediaan fasilitas terbatas, ditambah perabot yang menyita tempat menyebabkan ruang gerak bertambah sempit.

Saat mengerjakan tugas, belajar, tidur ataupun makan cenderung tidak nyaman dan tidak fokus, karena dilakukan tidak sesuai dengan tempatnya. Sehingga fungsi dari kamar kurang optimal bagi penghuninya. Oleh karena itu, diperlukan rancangan furniture multifungsi dengan persediaan cukup dan dimensi yang tidak besar untuk menopang kegiatan pada kamar kos. Perancangan menggunakan pendeketan ergonomi yang dicampur dengan acuan antropometri untuk merancang serta memakai acuan dari perancangan dan pengembangan produk. Pengambilan data dilakukan dengan beberapa metode yaitu wawancara/interview, observasi langung, dan pengukuran secara langsung. Metode interview dipilih agar memperoleh data yang berhubungan dengan kegiatan rutin penghuni kos pada kamar kos lebih akurat dan sesuai yang dibutuhkan. Selain aktivitas, digunakan untuk mencari tahu keinginan penghuni kos mengenai produk yang akan dirancang dan kelebihan serta kekurangan dari perabot kamar saat ini. Wawancara dilakukan untuk mengetahui kemampuan beli penghuni maupun pemilik usaha kos.Setelah perancangan selesai maka dilanjutkan dengan concept testing dan market testing. Pengujian ini dilakukan dengan metode 
wawancara kepada penghuni kos dan pemilik usaha kos. Kemudian dilanjutkan pada strategi pemasaran guna mengatur penjualan produk ini kedepannya. Langkah terakhir adalah pembuatan kesimpulan dan saran untuk penelitian ini.

\section{HASIL DAN BAHASAN}

Pada pengolahan data dilakukan identifikasi kebutuhan konsumen, hasil dari interview akan direkap dan dilakukan interprestasi data mentah dilanjutkan dengan pembobotan. Setelah menggabungkan data tersebut, dilanjutkan dengan HOQ. Berikut kebutuhan yang diperhatikan pada proses penelitian dari pendekatan $\mathrm{HOQ}$.

Tabel 1

Tabel Pengelompokan Identifikasi Kebutuhan Konsumen

\begin{tabular}{cc}
\hline $\begin{array}{c}\text { Kuat } \\
\text { Kualitas material }\end{array}$ & Kekuatan produk terjamin \\
\hline Murah & Harga terjangkau \\
\hline Aman & Keamanan saat pemakaian \\
\hline Indah & Desain yang bagus \\
Style & \\
Praktis & Multifungsi \\
\hline Memiliki banyak fitur \\
Terdapat tempat simpan \\
\hline $\begin{array}{c}\text { Tidak memakan banyak } \\
\text { tempat }\end{array}$
\end{tabular}

Beberapa kebutuhan konsumen hasil wawancara dikelompokan sesuai karakteristik yang sesuai, dan diambil kesimpulan seperti konsumen butuh produk yang kuat dan material berkualitas yang dikelompokan menjadi kekuatan produk terjamin. Setelah mendapatkan kebutuhan yang akan dimasukan kedalam $\mathrm{HOQ}$, melakukan penetapan metriks yang sesuai dengan kebutuhan konsumen sesuai dengan gambar 1 berikut.

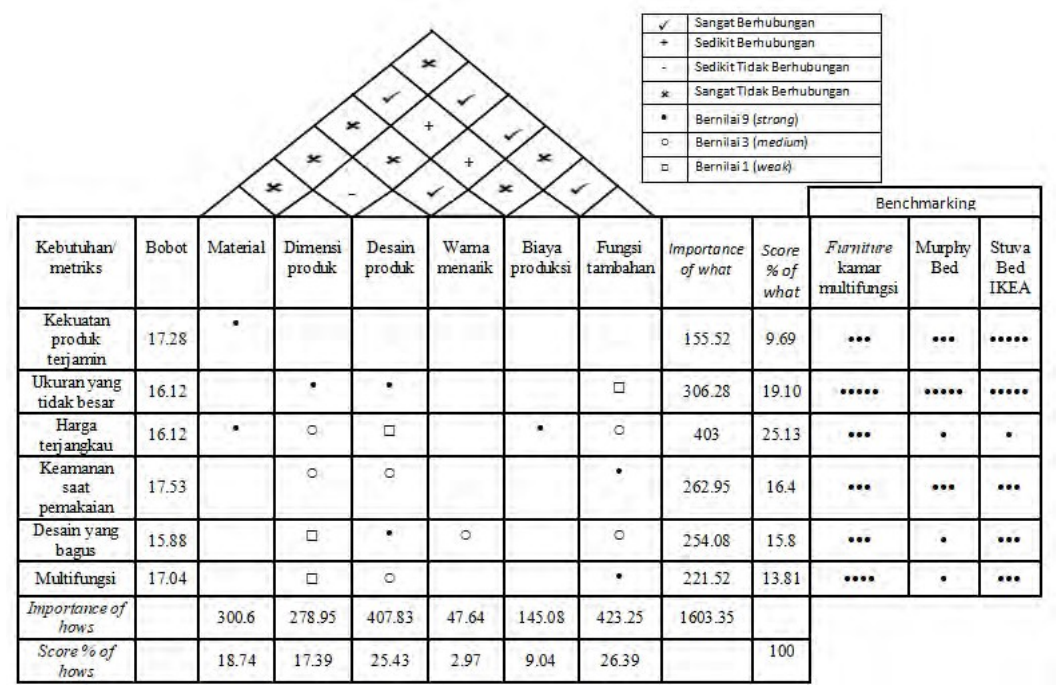

Gambar 1. House of quality.

Dari HOQ diatas terlihat beberapa kebutuhan yang diperlukan antara lain fungsi tambahan prosentase dengan $26.39 \%$, desain produk dengan prosentase $25.43 \%$, material 
dengan prosentase $18.74 \%$, dan dimensi produk dengan prosentase $17.39 \%$. Dari keempat kebutuhan tersebut, langkah berikutnya adalah concept generation. Langkah ini dilakukan dengan berbentuk bagan pohon. Dalam proses ini didapatkan 4 konsep yang akan dipilah kembali. Setelah dilakukan screening, diperoleh 4 konsep yang dapat lanjut ke concept scoring. Dalam langkah ini penilaian konsep memperoleh konsep terbaik, yaitu konsep 1 yang berupa furniture kamar multifungsi yang menggunakan desain modern dengan ukuran $2.2 \mathrm{~m} x$ $2 \mathrm{~m} \times 2 \mathrm{~m}$, menggunakan bahan baku full kayu serta memiliki ranjang dan meja lipat, memiliki laci dan lemari.

Setelah mendapat konsep terbaik, maka dilakukan pengujian konsep. Hasil dari pengujian mendapat $90 \%$ responden tertarik dengan konsep produk ini. Perancangan produk memerlukan ukuran yang sesuai dengan kondisi pemakai di Indonesia, maka dari itu data akan memakai dari antropometri dari orang Indonesia dengan persentil 95. Berikut spesifikasi produk pada tabel 2.

Tabel 2

Tabel Spesifikasi Produk dan Spesifikasi Antropometri

\begin{tabular}{|c|c|c|c|c|}
\hline Komponen & $\begin{array}{l}\text { Keterangan dimensi } \\
\text { antropometri }\end{array}$ & Ukuran $(\mathrm{cm})$ & $\begin{array}{c}\text { Ukuran acuan } \\
\text { antropometri }(\mathrm{cm})\end{array}$ & SD \\
\hline \multirow[b]{2}{*}{ Tempat tidur } & Tinggi popliteal & 50 & 48.79 & 3.86 \\
\hline & $\begin{array}{l}\text { Tinggi genggaman tangan ke } \\
\text { atas dalam posisi berdiri }\end{array}$ & 138 & 232.69 & 20.39 \\
\hline \multirow{3}{*}{ Meja lipat } & Tinggi siku dalam posisi duduk & 44 & 39.95 & 7.19 \\
\hline & Lebar sisi bahu & 66 & 51.46 & 5.71 \\
\hline & Lebar tangan & 9 & 9.76 & 0.9 \\
\hline \multirow{3}{*}{ Lemari } & Tinggi mata & 158 & 168.32 & 9.09 \\
\hline & Tinggi siku & 115 & 114.26 & 7.05 \\
\hline & $\begin{array}{l}\text { Tinggi genggaman ke atas } \\
\text { dalam posisi duduk }\end{array}$ & 100 & 152.1 & 15.17 \\
\hline \multirow{3}{*}{ Kursi gantung } & Panjang popliteal & 60 & 50.83 & 5.57 \\
\hline & Tinggi popliteal & 55 & 48.81 & 3.86 \\
\hline & Lebar pinggul & 45 & 43.5 & 5.14 \\
\hline \multirow{3}{*}{ Meja gantung } & Tinggi siku dalam posisi duduk & 40 & 39.95 & 7.19 \\
\hline & Lebar sisi bahu & 60 & 51.46 & 5.71 \\
\hline & Panjang lengan bawah & 65 & 56.87 & 8.31 \\
\hline
\end{tabular}

Setelah mendapat semua detil dari rancangan produk yang akan digunakan, maka dilanjutkan pada analisis aspek keuangan. Pada aspek ini akan menghitung jumlah HPP hingga harga jual yang akan ditetapkan. Profit yang diambil sebesar $5 \%$ dari HPP. Labor cost menggunakan asumsi pekerja sebanyak 3 orang dengan menghasilkan 17 unit/25 hari jam 
kerja. Harga jual produk sebesar Rp. 3.050.000. Berikut tabel rincian mengenai harga dari produk ini.

Tabel 3

Harga Jual Produk

\begin{tabular}{cc}
\hline Direct material cost & Rp, 2.543 .920 \\
\hline Direct labor cost & Rp. 352.941 \\
\hline Total (HPP) & Rp. 2.896 .861 \\
\hline Profit $5 \%$ & Rp. 144.843 \\
\hline Harga jual & Rp. 3.041.704 $\approx$ Rp. 3.050.000 \\
\hline
\end{tabular}

Perancangan produk juga memerlukan pembuatan strategi pemasaran, pada aspek ini penelitian memakai 2 pendekatan. Pertama, penggunaan STPD (Segmentasi, Target, Price, Diferensiasi). Kedua, menggunakan teori 4P yaitu product, price, place, and promotion.

\section{SIMPULAN}

Berdasarkan hasil penelitian, terdapat beberapa kesimpulan sebagai berikut:

1. Pembuatan furniture multifungsi untuk kamar kos dinilai sudah memenuhi kebutuhan, karena dengan permasalahan terbatasnya ruang kamar, perabot yang menyita tempat, dan barang berantakan tidak tersimpan dengan baik dapat diatasi dengan produk ini. Ditambah dengan pemakaian prinsip ergonomi agar kenyaman pemakai lebih optimal.

2. Kebutuhan konsumen dari hasil HOQ merupakan harga terjangkau, sehingga harga yang tercipta untuk produk ini sudah termasuk terjangkau dibanding dengan produk pesaing.

3. Dengan hadirnya rancangan furniture multifungsi ini, penggunaan kamar akan lebih optimal dan nyaman. Karena perabot mampu memberian kenyamanan yang ideal sesuai kondisi tubuh karena penggunaan data antropometri orang Indonesia. Selain itu terdapat banyak penyimpanan yang menyebabkan barang tidak berhamburan karena keterbatasan fasilitas.

4. Dari hasil pengujian konsep didapat 18 dari 20 narasumber menyukai produk ini.

5. Dengan harga penjualan Rp. 3.050 .000 untuk 1 full set perabot, masih belum ada yang berminat untuk membelinya.

Terdapat beberapa saran yang dapat dipertimbangkan untuk penelitian selanjutnya sebagai berikut:

1. Pemakaian bahan baku yang tidak hanya mengandalkan jenis kayu, tetapi diberi campuran seperti aluminium dsb. Selain guna mendapatkan harga murah, masa pakai juga menjadi lebihpanjang.

2. Melakukan product testing, pada penelitian ini belum mengikut sertakan konsep ini karena produk tidak direalisasikan.

3. Pada saat perancangan penelitian lebih baik untuk membuat konsep yang lebih bervariasi sehingga memiliki banyak alternatif dalam menentukan produk.

4. Memperbanyak jumlah interview terutama para pemilik/pembisnis kos, karena jumlah harga produk yang tergolong tinggi menjadi suatu halangan bagi para penghuni kos terutama mahasiswa untuk membeli produk ini.

5. Desain bisa dikembangkan lebih, agar membuat konsep lebih ringkas dan efesien dalam penggunan maupun dimensi yang lebih kecil. 


\section{PUSTAKA ACUAN}

Antropometri (2018). Data Antropometri Indonesia. Sumber: https://antropometri indonesia.org/index.php/detail/artikel/4/10/data_antropometri (akses 3 Okt 2019)

Dreyfuss, H. (1967), The Measure of Man: Human Factors in Design, Whitney Library of Design. Griffin, A. \& Hauser, J.R. (1993), The Voice of the Customer, Marketing Science, Vol. 12, No.1, pp.1-27.

Khomala, F. (2018), Perancangan Desain Meja Setrika Yang Ergonomis Pada Rumah Susun Penjaringan Sari 3 Surabaya, Universitas Surabaya.

Nurmianto, E. (2004), Ergonomi, Konsep Dasar dan Aplikasinya: Tinjauan Anatomi, Fisiologi, Antropometri, Psikologi, dan komputasi Untuk Perancangan Kerja dan Produk. Penerbit Guna Widya. Surabaya.

Pugh, S. (1991), Total Design - Integrated Methods for Successful Product Engineering. Addison- Wesley Pub.

Katadata (2018). Jumlah Penduduk Indonesia. Sumber: https://databoks.katadata.co.id/data publish/2018/07/08/jumlah-penduduk-indonesia-akan-mencapai-puncaknya-pada2062 (akses 28 Feb 2019) 